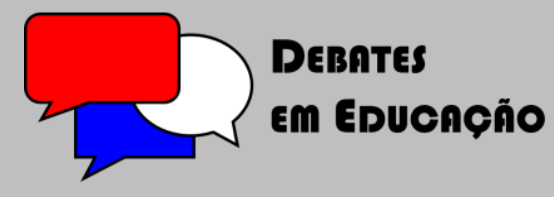

ISSN Eletrônico: 2175-6600

Vol. 10 | №. 20 | Jan./Abr. | Ano 2018

Flavio Pereira de Jesus Universidade Federal do Espírito Santo

(UFES)

flavio2128@yahoo.com.br

\section{MEDIAÇÃO E DESENVOLVIMENTO: CONTRIBUIÇÕES DO PIBID NO PROCESSO DE ENSINO E APRENDIZAGEM}

\section{RESUMO}

O PIBID foi criado pelo Governo Federal em 2007. A Escola Estadual de Ensino Fundamental e Médio Wallace Castello Dutra, no município de São Mateus (ES), passou a contar com o trabalho dos bolsistas em 2013. Esta pesquisa busca traçar um perfil da atuação do programa na escola sob o ponto de vista dos próprios pibidianos. O referencial teórico dá destaque à importância da linguagem nos processos de mediação, embasada principalmente nas ideias de Vygotsky. Esta averiguação é feita sob o aspecto qualitativo, com análise de discurso na perspectiva sócio-histórica. Concluiu-se que, como fatores determinantes na qualidade do trabalho desenvolvido pelos bolsistas, estão o gosto que tinham, ou adquiriram, pela sala de aula, as dicas que os regentes titulares compartilham, interação com o professor e com os estudantes, desenvolvimento de atividades experimentais, vocabulário mais simples, entre outros.

Palavras-chave: PIBID. Mediação. Formação de professores.

\section{MEDIATION AND DEVELOPMENT: PIBID CONTRIBUTIONS IN THE TEACHING AND LEARNING PROCESS}

\begin{abstract}
The PIBID was created by the Federal Government in 2007. The State School of Elementary and Middle School Wallace Castello Dutra, in the municipality of São Mateus (ES), started to count on the work of the scholars in 2013. This research seeks to a profile of the program's performance in the school from the point of view of the pibidians themselves. The theoretical reference emphasizes the importance of language in mediation processes, based mainly on Vygotsky's ideas. This inquiry is made under the qualitative aspect, with analysis of discourse in the socio-historical perspective. It was concluded that, as determinants in the quality of the work carried out by the fellows, are the taste they had, or acquired, in the classroom, the tips that the titular regents share, interaction with the teacher and with the students, development of activities experimentation, simpler vocabulary, among others.
\end{abstract}

Keywords: PIBID. Mediation. Teacher training.

Submetido em: 03/02/2018

Aceito em: 30/03/2018

DOI: 10.28998/2175-6600.2018v10n20p312 


\section{RESUMO DA DISSERTAÇÃO}

O Programa Institucional de Bolsa de Iniciação à Docência - PIBID foi criado pelo Governo Federal em 2007. A Escola Estadual de Ensino Fundamental e Médio Wallace Castello Dutra, em Guriri, município de São Mateus (ES), passou a contar com o trabalho dos bolsistas do PIBID no ano de 2013. Dentro desse contexto, esta pesquisa busca traçar um perfil da atuação do programa na escola e levantar os motivos pelos quais o trabalho dos bolsistas desfruta de grande aceitação. Esses motivos são analisados sob o ponto de vista dos próprios pibidianos. Por meio de questionários e entrevistas, esta investigação quis apurar as impressões, sentimentos e inspirações dos próprios bolsistas em relação ao trabalho que eles desenvolvem na escola, como eles contribuem no aprendizado dos estudantes de Ensino Médio, de que maneira o PIBID influencia na formação do futuro professor, como é o relacionamento com o estudante e com o professor regente titular, que tipos de atividades são desenvolvidas, pontos positivos e pontos frágeis, se a atuação dos bolsistas interfere, de alguma maneira, nos resultados obtidos pela escola em avaliações externas. O objetivo principal é analisar como o trabalho dos bolsistas contribui para melhorar o processo de ensino-aprendizagem nas turmas de Ensino Médio. Esta pesquisa foi motivada pela curiosidade em investigar os motivos dos elogios à atuação dos pibidianos. A Escola Wallace Castello Dutra foi definida como campo de pesquisa por favorecer o acompanhamento do grupo, uma vez que o pesquisador é professor efetivo na escola desde 2014 e é residente no mesmo bairro. O referencial teórico dá destaque à importância da linguagem nos processos de mediação, embasada principalmente nas ideias de Vygotsky. No aspecto metodológico, esta averiguação é feita sob o aspecto qualitativo, com análise de discurso na perspectiva sócio-histórica. Por fim, conclui-se que, como fatores determinantes na qualidade do trabalho desenvolvido pelos bolsistas, estão o gosto que tinham, ou adquiriram, pela sala de aula, as dicas que os regentes titulares compartilham, interação com o professor e com os estudantes, desenvolvimento de atividades experimentais, vocabulário mais simples, aprofundamento nos estudos acadêmicos, busca pela contextualização das atividades, empenho em utilizar recursos além do quadro branco, planejamento da regência e autonomia dada pelo professor regente titular.

\section{REFERÊNCIAS}

ALTHUSSER, Louis. Ideologia e Aparelhos Ideológicos de Estado. Lisboa: Presença, 1970. 
ARAÚJO, Carlos Alberto Ávila. A ciência como forma de conhecimento. Ciências \& Cognição. Belo Horizonte, v. 08, p.127-142, ago. 2006.

ARAÚJO, Carlos Henrique; LUZIO, Nildo. Avaliação da Educação Básica: em busca da qualidade e equidade no Brasil. Brasília: Instituto Nacional de Estudos e Pesquisas Educacionais Anísio Teixeira, 2005.

BARBOSA, Najla Veloso. Currículo e diversidade cultural. Brasília: Curso PIE/UnB, 2003.

BAUMAN, Zygmunt. Tempos líquidos. São Paulo: Jorge Zahar Editor, 2007.

BOGDAN, Robert; BIKLEN, Sari. Investigação qualitativa em educação. Porto: Porto Editora, 1994.

BONJORNO, José Roberto; BONJORNO, Regina de Fátima Souza Azenha; BONJORNO, Valter; RAMOS, Clinton Marcico; PRADO, Eduardo de Pinho; CASEMIRO, Renato.

Física: termologia, óptica, ondulatória. 2. ed. São Paulo: FTD, 2013.

BRASIL. Lei de Diretrizes e Bases da Educação Nacional. Lei número 9394, 20 de dezembro de 1996.

BRASIL. Ministério da Educação. Portaria N 46, de 11 de abril de 2016. Dispõe sobre o regulamento do Programa Institucional de Bolsa de Iniciação à Docência - PIBID. Brasília: SESU, 2016.

BRASIL. Ministério de Educação. Portaria Normativa N³8, de 12 de dezembro de 2007. Dispõe sobre o Programa Institucional de Bolsa de Iniciação à Docência - PIBID. Brasília: MEC, 2007.

BRASIL. Ministério de Educação. Portaria N 84, de 14 de junho de 2016. Dispõe sobre o Programa Institucional de Bolsa de Iniciação à Docência - PIBID. Brasília: MEC, 2016.

BRASIL. Ministério da Educação, Secretaria de Educação Média e Tecnológica.

Orientações curriculares para o Ensino Médio: ciências da natureza, matemática e suas tecnologias. Brasília, DF, 2000. v.2. p.45.

BRIGGS, Asa; BURKE, Peter. Uma história social da mídia: De Gutenberg à internet. Rio de Janeiro: Jorge Zahar, 2006. 
COELHO, Geide Rosa. Estágio supervisionado. Vitória: Ufes, 2011.

ENGELS, Friedrich. Sobre o Papel do Trabalho na Transformação do Macaco em Homem. In: ENGELS, F. O Papel do Trabalho na Transformação do Macaco em Homem. São Paulo: Global, 1986. p.11-37.

EPSTEIN, Isaac. Cibernética. São Paulo: Ática, 1986.

EPSTEIN, Isaac. O Signo. São Paulo: Ática, 1990.

ESCOLA WALLACE DUTRA É A MELHOR AVALIADA NO ENEM NA REDE PÚBLICA. Tribuna do Cricaré, São Mateus, 15 out. 2016. p.8

ESPÍRITO SANTO. EEEFM Wallace Castello Dutra. Projeto Político Pedagógico. São Mateus: [s.n.], 2011.

ESPÍRITO SANTO. Secretaria Estadual da Educação. Currículo básico da escola estadual. Vitória: Sedu, 2009.

FREIRE, Paulo. Educação como prática da liberdade. Rio de Janeiro: Paz e Terra, 1991.

FREITAG, Barbara. Escola, Estado e Sociedade. 4. ed. São Paulo: Moraes, 1980.

FREITAS, Maria Teresa de Assunção. A abordagem sócio-histórica como orientadora da pesquisa qualitativa. Cadernos de Pesquisa. São Paulo, n.116, p.21-39, jul.2002.

G1. Estudantes do intercâmbio do governo do ES embarcam para Inglaterra e Chile. Disponível em: <https://g1.globo.com/espirito-santo/educacao/noticia/estudantes-dointercambio-do-governo-do-es-embarcam-para-inglaterra-e-chile.ghtml>. Acesso em: 2 set. 2017.

GADOTTI, Moacir. Perspectivas atuais da educação. Porto Alegre: Artes Médicas, 2001.

GALLIANO, Antônio Guilherme. O método científico: teoria e prática. São Paulo: Harbra, 1986. 
GOÑI, Jesús. Do currículo por conteúdos temáticos ao currículo por aprendizagens, Tomo I. Jaén: Fundação Universitária Iberoamericana, 2012.

GRAMSCI, Antonio. Os intelectuais e a organização da cultura. 4. ed. Rio de Janeiro: Civilização Brasileira, 1982.

LOMBARDI, José Claudinei. Marx \& Engels: Textos sobre educação e ensino.

Campinas: Navegando, 2011.

LIBÂNEO, José Carlos. Organização e gestão da escola: teoria e prática. 5. ed. Goiânia: Alternativa, 2004.

MARCONI, Marina de Andrade; LAKATOS, Eva Maria. Fundamentos de Metodologia Científica. 5. ed. São Paulo: Atlas, 2003.

MENDES, Wilson. Pesquisa aponta que $63 \%$ dos pais não querem que seus filhos sejam professores. Rio de Janeiro: Globo, 2013. Disponível em:

<https://extra.globo.com/noticias/rio/pesquisa-aponta-que-63-dos-pais-nao-querem-queseus-filhos-sejam-professores-10366211.html>. Acesso em: 25 set. 2017.

MOLON, Susana Inês. Questões metodológicas de pesquisa na abordagem sóciohistórica. Informática na educação: teoria \& prática. Porto Alegre, v.11, n.1, p. 56-68, janjun. 2008.

MONTEIRO, Eduardo; STEIN, Márcia. Caderno de roteiros 1 - Programa de Formação Continuada Multicurso Ensino Médio - Matemática - Governo do Estado do Espírito Santo. Vitória, v.1, n.1, p. 17-21, mai.2008.

MONTEIRO, Eduardo; STEIN, Márcia. Caderno de roteiros 3 - Programa de Formação Continuada Multicurso Ensino Médio - Matemática - Governo do Estado do Espírito Santo. Vitória, v.1, n.3, p. 17-22, out.2008.

MOTA, Carlos Ramos; BARBOSA, Najla Veloso. O currículo para além das grades construindo uma escola em sintonia com seu tempo. MEC/TV Escola/Salto para o futuro. Brasília, junho de 2004.

NOVAIS, Elaine Lopes. É possível ter autoridade em sala de aula sem ser autoritário? Linguagem \& Ensino, v. 7, n. 1, p.15-51, 2004. 
PASSAMANI, Maria Hermínia Baião. Fundamentos da Educação II: didática. Vitória: Universidade Federal do Espírito Santo, 2010.

PINEL, Hiran. Fundamentos da Educação I: psicologia da educação. Vitória:

Universidade Federal do Espírito Santo, 2009.

PRÊMIO PROFESSORES DO BRASIL. Apresentação. Disponível em:

<http://premioprofessoresdobrasil.mec.gov.br/\#apresentacao>. Acesso em: 20 out. 2017.

RODRIGUES, João Assis. Fundamentos da Educação III: Introdução à Filosofia. Vitória: Universidade Federal do Espírito Santo, 2010.

RODRIGUES, Neidson. Da mistificação da escola à escola necessária. 8. ed. São Paulo: Cortez, 1998.

SACRISTÁN, José Gimeno. O currículo: os conteúdos de ensino ou uma análise da prática? In: SACRISTÁN, J.G.; GÓMEZ, A.I.P. Compreender e transformar o ensino. Porto Alegre: Artmed, 1998.

SAMSUNG NEWSROOM. Samsung divulga projetos vencedores da etapa regional da 3a edição do Prêmio Respostas Para o Amanhã. Disponível em:

$<$ https://news.samsung.com/br/samsung-divulga-projetos-vencedores-da-etapa-regionalda-3a-edicao-do-premio-respostas-para-o-amanha>. Acesso em: 5 fev. 2017.

SANTIAGO, Estrella de la Rosa. Conceitualização e classificação dos métodos de aprendizagem. Jaén: Fundação Universitária Iberoamericana, 2012.

SEDU. Estudantes e professor da rede estadual são vencedores do Prêmio Ecologia 2016. Disponível em: <http://sedu.es.gov.br/Not\%C3\%ADcia/estudantes-e-professor-darede-estadual-sao-vencedores-do-premio-ecologia-2016>. Acesso em: 7 fev. 2017.

SILVA, Tomás. Documentos de identidade: uma introdução às teorias do currículo. Belo Horizonte: Autêntica, 2000.

TEDESCO, Juan Carlos. Educação e novas tecnologias: esperança ou incerteza? São Paulo: Cortez, 2004.

TELES, Maria Luiza Silveira. Curso Básico de Sociologia da Educação. 2. ed. Petrópolis: Vozes, 1989. 
TRIPODI, Tony; FELLIN, Philip; MEYER, Henry. Análise da pesquisa social. Rio de Janeiro: Francisco Alves, 1975.

UNIVERSIDADE FEDERAL DO ESPÍRITO SANTO. Edital 001/2016 - Universidade

Federal do Espírito Santo/Coordenação do Programa Institucional de Bolsa de Iniciação à Docência PIBID/Campus Ceunes. São Mateus, 2016.

VALENTE, José Armando. Informática na educação no Brasil: análise e contextualização histórica. In: VALENTE, José Armando (org.). O computador na sociedade do conhecimento. Campinas: UNICAMP/NIED, 1999.

VASCONCELLOS, Celso dos Santos. Coordenação do trabalho pedagógico: do projeto político-pedagógico ao cotidiano da sala de aula. 5. ed. São Paulo: Libertad, 2004.

VYGOTSKY, Lev Semenovitch. A formação social da mente. 7. ed. São Paulo: Martins Fontes, 2007.

VYGOTSKY, Lev Semenovitch. Pensamento e linguagem. São Paulo: Martins Fontes, 1989.

ZABALA, Antoni. A prática educativa: como ensinar. Porto Alegre: Artmed, 1998. 